\title{
Quando é preciso saber que não sabemos o suficiente: Alfabeto maldito enquanto um exercício de desleitura
}

\author{
When You Need to Know that We Don't Know Enough: \\ Damn Alphabet While a Sloppy Exercise
}

\section{Cuando necesita saber que no sabemos lo suficiente: Maldito alfabeto mientras haces un ejercicio descuidado}

Maykson Cardoso *

Universidade Federal do Rio de Janeiro, Brasil

RESUMO: Este texto foi escrito como apresentação do catálogo de Alfabeto maldito, exposição realizada por Jorgge Menna Barreto e Joélson Buggilla entre julho e agosto de 2019, no SESC-Paraty, que tive a oportunidade de acompanhar também como curador. Na primeira parte, faz-se um percurso breve do trabalho de cada um dos artistas, pensando no ponto de encontro que possibilitou a construção de um trabalho comum; na segunda, propõe-se, brevemente, um caminho para uma experiência de "[des]leitura", orientada por esse alfabeto muito singular e, por princípio, indecifrável. A segunda parte do texto foi, também, o texto de parede da exposição, de sorte que o seu formato obedece às exigências desses dois gêneros textuais muito específicos, marcados pela reflexão sucinta, sugestiva, mais "direta ao ponto".

PALAVRAS-CHAVE: Alfabeto maldito; Jorgge Menna Barreto; Joélson Buggilla

\footnotetext{
* Maykson Cardoso é doutorando em História da Arte pelo Programa de Pós-Graduação em Artes Visuais da Universidade Federal do Rio de Janeiro. E-mail: maykson.sousa@gmail.com. Orcid: https://orcid.org/0000-0002-7916-4029
} 
ABSTRACT: This text was written as an introduction to the catalogue of Alfabeto maldito, an exhibition by Jorge Menna Barreto and Joélson Bugila between July and August 2019 at SESC-Paraty - which I took part in as curator. The first part is a brief overview of each artist's work, from a standpoint of the intersection that allowed the creation of this joint work; the second briefly proposes a route to an exercise of "[mis]reading", guided by a unique alphabet that is, in principle, indecipherable. The second part of the text was also the exhibition's wall text, as such the text follows the requirements for the form of both of these specific textual genres, marked by succinct and suggestive reflection, while being to the point.

KEYWORDS: Damn Alphabet; Jorgge Menna Barreto; Joélson Buggilla

RESUMEN: Este texto fue escrito como una presentación del catálogo de Alphabet maldito, una exposición realizada por Jorgge Menna Barreto y Joélson Buggilla entre julio y agosto de 2019, en SESC-Paraty, que tuve la oportunidad de seguir como curador. En la primera parte, se realiza una breve descripción del trabajo de cada artista, pensando en el punto de encuentro que permitió la construcción de una obra común; En el segundo, proponemos brevemente un camino hacia una experiencia de "lectura", guiada por este alfabeto único y, en principio, indescifrable. La segunda parte del texto fue también el texto de la pared de la exposición, por lo que su formato cumple con las demandas de estos dos géneros textuales muy específicos, marcados por una reflexión sucinta, sugerente, más "al punto".

PALABRAS CLAVE: Maldito alfabeto; Jorgge Menna Barreto; Joélson Buggilla

Citação recomendada:

CARDOSO, Maykson. Quando é preciso saber que não sabemos o suficiente: Alfabeto maldito enquanto um exercício de desleitura. Poiésis, Niterói, v. 20, n. 34, p. 227-232, jul./dez. 2019. [https://doi.org/10.22409/poiesis.v20i34.38723]

Maykson Cardoso. Quando é preciso saber que não sabemos o suficiente... 


\section{Os desafios da arte e da estética no século XXI}

\section{Do mundo da forma à forma do mundo}

Entre todos os pontos de partida que se pode tomar para começar a compreender A/fabeto maldito, há um que diz muito sobre as forças que, aí, se colocam em jogo: o fato de que esta é a primeira colaboração que Joélson Buggilla e Jorgge Menna Barreto assinam conjuntamente, enquanto "trabaIho de arte". Por isso, é possível começar pensando que este alfabeto particular surge primeiramente de um encontro sensível que propiciou um exercício de depuração das questões que ambos os artistas vêm desenvolvendo ao longo de suas trajetórias. O que, sem sombra de dúvidas, leva a passar panoramicamente por certos trabalhos que dão a ver uma relação mais direta entre aquilo que fizeram e o que ora apresentam.

Os interesses de Jorgge Menna Barreto pela linguagem, pela tradução, pela construção de uma relação complexa destas com a site-specificity e, ultimamente, também com 
o cultivo agroflorestal e o ativismo alimentar, têm resultado em uma série de projetos que vêm se complexificando a cada novo desdobramento. Entre eles, destacamse, nos últimos anos, os Sucos específicos (2014), feitos com plantas selvagens comestíveis cujas propriedades estão relacionadas às especificidades do lugar onde crescem; Restauro (2016), que integrou a $32^{\mathrm{a}}$ Bienal de São Paulo, onde o artista instalou um restaurante que oferecia comida feita com alimentos cultivados em agroflorestas situadas nos arredores da metrópole, ao mesmo tempo que dava lugar a uma série de ações educativas que, entre outras coisas, trazia semanalmente agrofloresteiros para falar com o público participante; e, por último, Londelion (2017), realizado na Serpentine Gallery, em Londres, que consistiu na fabricação de sorvetes de dente de leão - dandelion, em inglês, talvez a mais conhecida das chamadas "ervas daninhas" -, presença marcante nos parques de Londres. Esses projetos dão a dimensão de uma preocupação evidente para o artista, totalmente alinhada à sua tomada de posição em relação à responsabilidade ambiental e a outras possibilidades de produção de alimentos que fazem frente aos processos de devastação ambiental.
Por sua vez, os trabalhos mais recentes de Joélson Buggilla dão testemunho de um tipo de expressão que é capaz de combinar uma sorte de pensamento gráfico às experimentações escultóricas, de colagem e, em alguma medida, pictóricas, sem deixar de estar atento às exigências da ordem do dia. Isto é, o artista tem feito um uso muito pertinente da forma e do conteúdo, sem que este seja valorizado em detrimento daquela. No último ano, sua pesquisa exaustiva com jornais impressos, especialmente os brasileiros, deu corpo a um conjunto de trabalhos que, se de um lado lidava com suas matérias cinzentas (ou seja, com a materialidade do papel, mas, também, de modo figurado, com as matérias jornalísticas), de outro procurava insistentemente encontrar ocasião para a inventividade nas brechas entre uma coluna de jornal e outra - as quais o artista chamou de "áreas livres". Assim, se em alguns trabalhos o artista dá ênfase à violência cotidiana das cidades, expressa em cada palavra das manchetes que ele recorta e coleciona para compor textos em colagens, em outros, ele recorta e coleciona as "áreas livres" para construir uma paisagem pictórica vibrante, como quem buscasse o último canto de li-

Maykson Cardoso. Quando é preciso saber que não sabemos o suficiente... 
berdade para reinventar o mundo em meio à terra arrasada das notícias dos jornais ${ }^{1}$.

Quer dizer... é bom que se tenha em mente que este Alfabeto maldito é resultado de dois modos diferentes de pensar e se haver com o mundo da forma e, portanto, com os problemas da arte, mas de comum acordo no que se refere à responsabilidade ética daqueles que se esmeram em buscar - ou apostar em - outras saídas, mesmo quando parece não haver nenhuma saída possível. Assim, mesmo diante da diferença em relação ao modo como trabalham o "mundo da forma", Joélson Buggilla e Jorgge Menna Barreto se encontram na esperança de mudar minimamente a forma do mundo. $\mathrm{E}$, com isto, entenda-se: mudar minimamente o modo como temos vivido no mundo, mudar a perspectiva a partir da qual o olhamos e nos relacionamos com ele.

\section{Um alfabeto indecifrável}

Alfabeto maldito é um título que pode ser imediatamente relacionado a alguma instância da letra. Mas, se assim o for, não surtirá outro efeito senão o de uma rasteira em quem se dispõe a olhá-lo a partir dessa perspectiva. É que ao confrontar o título com o trabalho, vê-se que não se está, aí, diante de quaisquer letras reconhecíveis: não há, neste alfabeto, nada que represente graficamente as unidades sonoras - os fonemas - que compõem uma língua. Mesmo sua ordem é orgânica, mutável, selvagem: não começa no $a$, não termina no $z$, e talvez, sequer, tenha fim... seja um trabaIho em curso. E muito embora as imagens possam sugerir um código secreto a ser desvendado - como se fossem hieróglifos ou ideogramas -, qualquer tentativa neste sentido será igualmente frustrada.

Acontece que este alfabeto é, por princípio, indecifrável. O que se deve ao fato de que ele surgiu como uma tentativa de fazer valer a experiência do humano diante de uma linguagem que the é completamente estranha e inacessível: a linguagem secreta das plantas. Por isso, diante dele, e dessas letras-plantas, não se está diante de uma experiência de leitura, mas, antes, de desleitura - como, aliás, Jorgje Menna Barreto nomeou outro de seus projetos; uma experiência que dá lugar à desconstrução de um modo de ler humano, demasiado humano. É por isso que Alfabeto maldito nos cons- 
trange a tomar uma posição: a de que não sabemos o suficiente sobre o mundo, ou melhor, a de que o nosso saber se limita à nossa condição de humanos constituídos em uma e por uma linguagem que é somente nossa. Neste sentido, o pensamento ameríndio de alguns povos poderia vir ao nosso socorro para finalmente nos oferecer outra concepção do mundo, tal como nos ensina Eduardo Viveiros de Castro, resumindo-a, em poucas palavras, já no início de um de seus artigos: "a concepção de um mundo que é habitado por diferentes espécies de sujeitos ou pessoas, humanas e não-humanas, que o apreendem segundo pontos de vista distintos" (VIVEIROS DE CASTRO, 2004) ${ }^{2}$.

O projeto Alfabeto maldito é fruto de uma experiência imersiva de Joélson Bugila na Agrofloresta Sítio São José, em Paraty, Rio de Janeiro, em parceria com Jorge Menna Barreto, que acompanhou cada passo dessa experiência. Os artistas contaram com a colaboração inestimável do mateiro Jorge Ferreira, conhecedor da mata nativa da região, e do fotógrafo Rafael Guedes, responsável pelos registros que deram origem às imagens do trabalho e da publicação. Em todas as etapas, o projeto recebeu o apoio do Sesc de Paraty, que também acolheu a exposição.

\section{Notas}

${ }^{1}$ Recomendo, também, a leitura do texto "Sketch crítica sobre as coisas que aprendi com os trabalhos recentes de Joélson Buggilla, ou: de outros modos de falar sobre o trabalho dos outros", no qual me detenho mais na produção recente de Joélson Buggilla. $O$ texto pode ser lido no seguinte link: https: / / bit.ly/2IlWHQQ.

${ }^{2}$ VIVEIROS DE CASTRO, Eduardo. Perspectivismo e multiculturalismo na América Latina. $O$ que nos faz pensar, n. 18 , set. 2004. 